\title{
Experimental investigation of drag reduction by forward facing high speed gas jet for a large angle blunt cone at Mach 8
}

\author{
BALLA VENUKUMAR and K P J REDDY \\ Department of Aerospace Engineering, Indian Institute of Science, \\ Bangalore 560012 \\ e-mail: laser@aero.iisc.ernet.in
}

\begin{abstract}
Substantial aerodynamic drag, while flying at hypersonic Mach number, due to the presence of strong standing shock wave ahead of a large-angle bluntcone configuration, is a matter of great design concern. Preliminary experimental results for the drag reduction by a forward-facing supersonic air jet for a $60^{\circ}$ apexangle blunt cone at a flow Mach number of 8 are presented in this paper. The measurements are carried out using an accelerometer-based balance system in the hypersonic shock tunnel HST2 of the Indian Institute of Science, Bangalore. About $29 \%$ reduction in the drag coefficient has been observed with the injection of a supersonic gas jet.
\end{abstract}

Keywords. Aerodynamic drag; hypersonic flow; shock tunnel; air jet; force balance; shock interaction.

\section{Introduction}

It is well known that in order to address the severe heating problems encountered during the atmospheric flight of hypersonic vehicles, large-angle blunt-cone configurations are preferred at the cost of enhanced aerodynamic drag, due to the presence of the nearly normal standing shock wave in front of the vehicle. The enhanced wave-drag increases the demand for propellant during the ascent phase (Peter \& Donn 1987). Thus, the management of the aerodynamic drag encountered by the blunt body configurations of hypersonic vehicles is of significant interest in order to reduce the cost of space travel or enhance the range of supersonic missiles. Many techniques have been proposed to reduce the wave drag essentially based on the aerodynamic drag management by controlling the flowfields around the high speed bodies. Some of these techniques include the use of aerospikes with different aerodiscs (Menezes et al 2003), gas injection at the stagnation region (Sahoo et al 2005), multi-step base design (Menezes et al 2005) and energy deposition into the flow (Satheesh \& Jagadeesh 2005). We have been investigating these techniques experimentally in recent years in the hypersonic shock tunnel HST2 of the Indian Institute of Science, Bangalore, numerically using the CFX TASCFlow code. A review of these results was presented at the 11th Asian Congress of Fluid Mechanics (Reddy et al 2006). 
Drag reduction by a counterflowing supersonic jet emanating from the stagnation point of a blunt body flying at hypersonic Mach number is one more powerful technique for the effective reduction of drag as well as for aerodynamic heat transfer to the body (Josyula et al 2001; Hayashi \& Asoy 2003; Balla Venukumar et al 2006). Drag reduction by counterflowing supersonic jet for a $60^{\circ}$ apex angle blunt cone is investigated in the HST2 shock tunnel at a flow Mach number of 8 . Some of the results of this study are reported briefly in this paper. More detailed results as well as the basic physics of the drag reduction by the counterflow supersonic jet are presented in a recent publication (Balla Venukumar et al 2006).

\section{Experimental facility}

The experimental investigations are carried out in the hypersonic shock tunnel HST2 shown schematically in figure 1. The working of the shock tunnel and the procedure for estimating its performance are presented in detail in an earlier publication (Reddy et al 1996). The HST2 shock tunnel consists of a shock tube (50-mm internal diameter) divided into driver and driven sections separated by a metallic diaphragm. The shock tube is connected to the wind-tunnel portion consisting of a hypersonic nozzle, test section and dump tank through a paper diaphragm at the entrance of the nozzle. The hypersonic flow is produced by the convergent-divergent conical nozzle of $10^{\circ}$ divergence angle and $300 \mathrm{~mm}$ exit diameter. The nozzle produces Mach 5.75 flow in the test section in straight-through mode of operation and hypersonic flow of Mach numbers 8,10 and 12 are obtained in the reflected mode of operation by attaching an appropriate throat at the entrance of the nozzle. The experiments described in this paper are carried out in the reflected mode of operation at Mach 8. The hypersonic flow goes through a $450 \mathrm{~mm}$ long test section of $300 \times 300 \mathrm{~mm}$ square cross section before entering

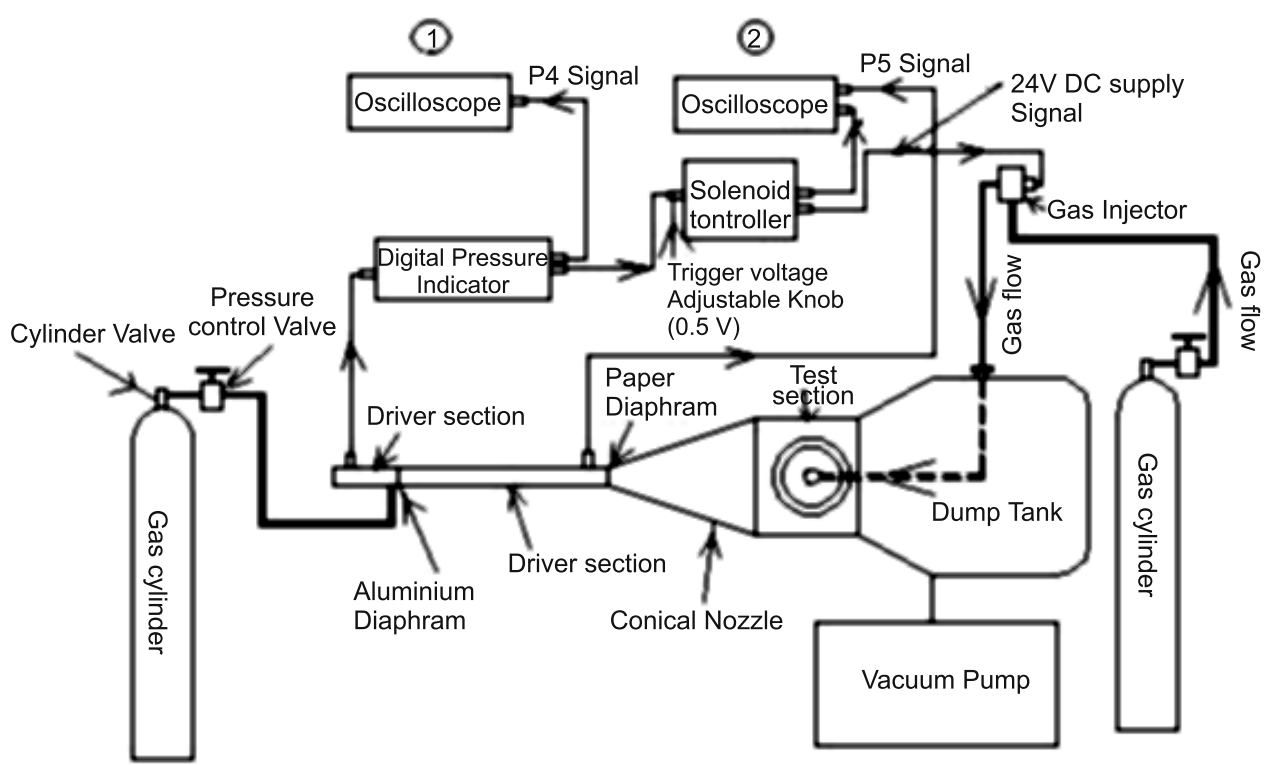

Figure 1. Schematic diagram of the HST2 hypersonic shock tunnel equipped with the gas injection system for generating the supersonic gas jet from the stagnation point of the model in the test section. 
(a)
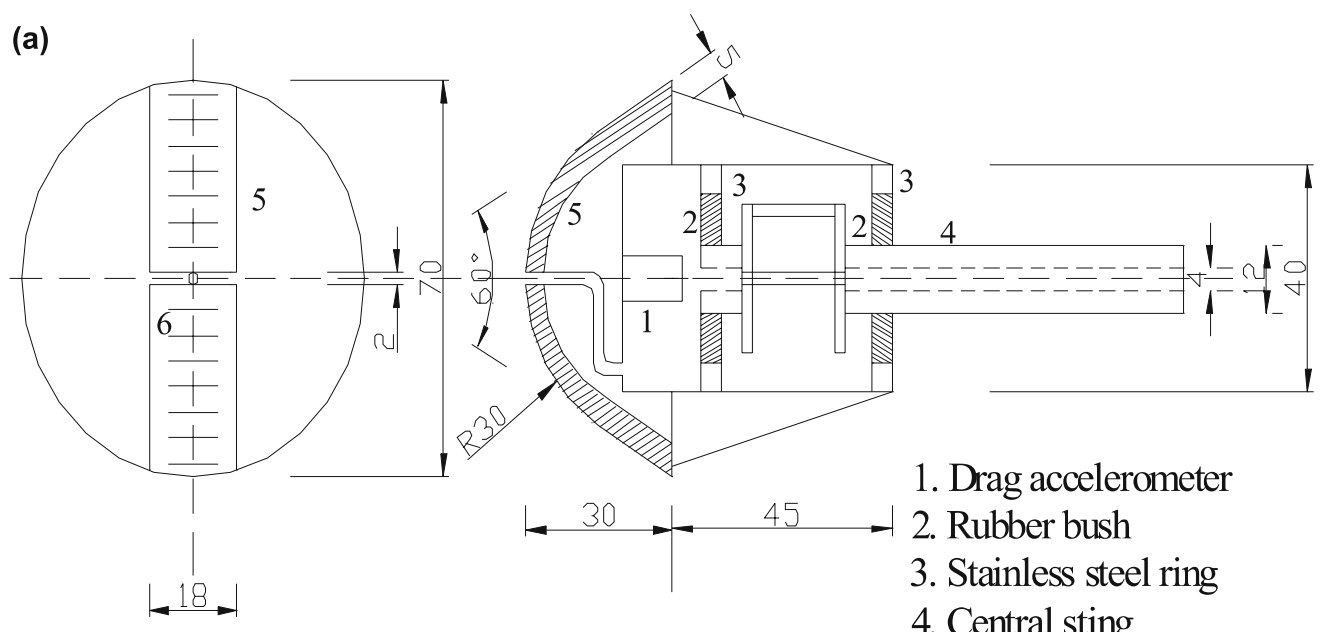

All dimensions are in 'mm'.

1. Drag accelerometer

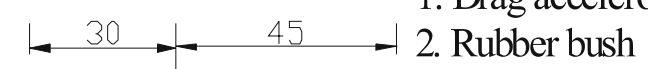

3. Stainless steel ring

4. Central sting

5. Macor strip

6. Platinum thin film sensors

(b)

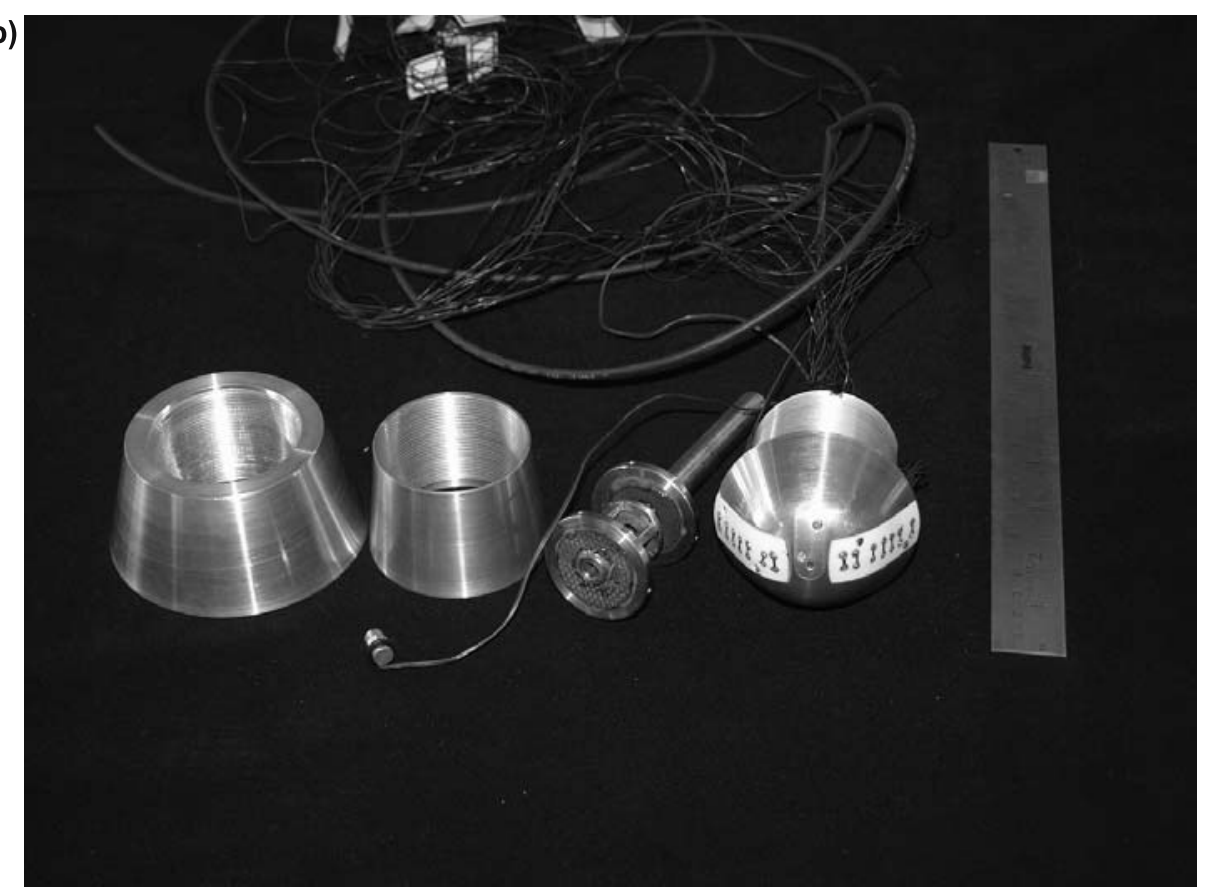

Figure 2. (a) Schematic diagram and (b) photograph of a $60^{\circ}$ apex-angle blunt cone model fitted with platinum thin film gauges and accelerometer balance system.

the $1000 \mathrm{~mm}$ diameter dump tank. The wind tunnel portion of the shock tunnel is evacuated to $10^{-6}$ mbar pressure by using a rotary pump-diffusion pump combination. The hypersonic flow in the test section is calibrated using the pitot rake traversing along the axis parallel to the flow. The details of the calibration procedure are presented in a previous publication (Reddy et al 1996). 
(a)

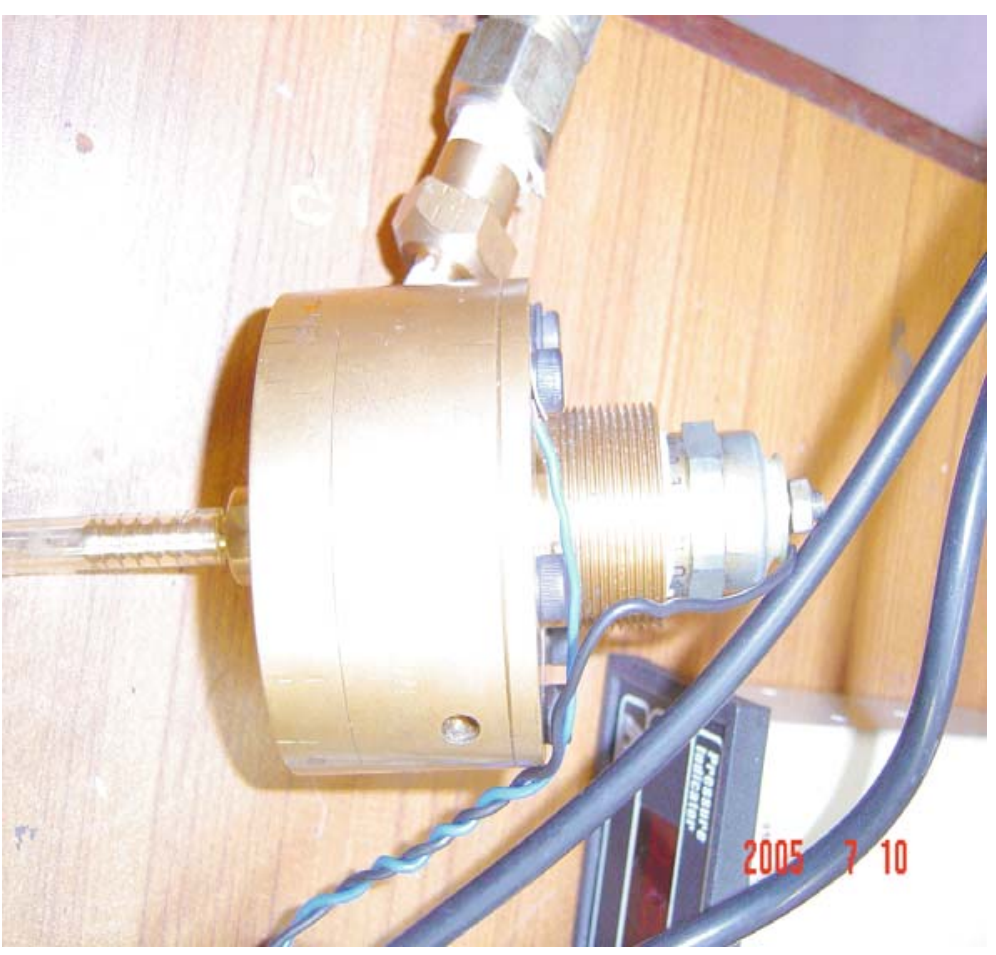

(b)

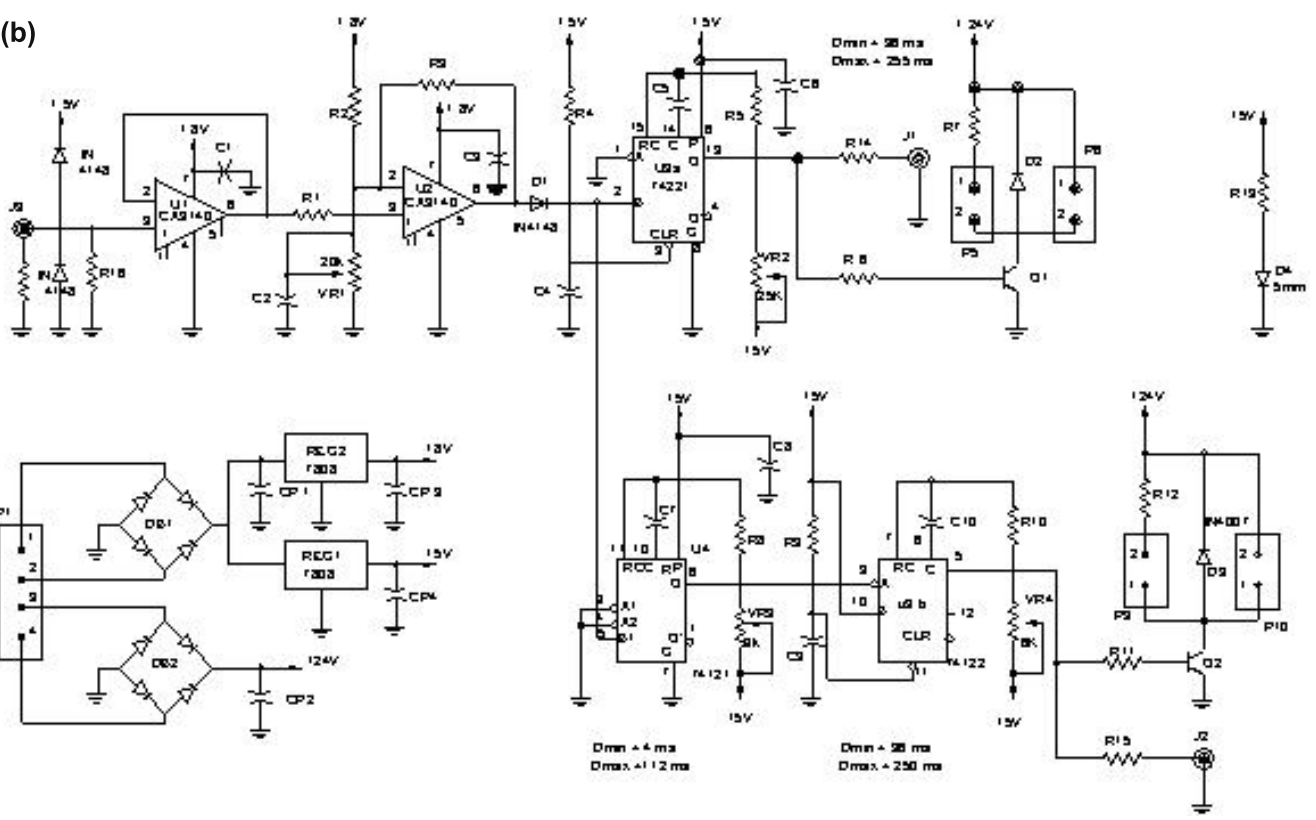

Figure 3. (Caption on facing page.) 
(c)

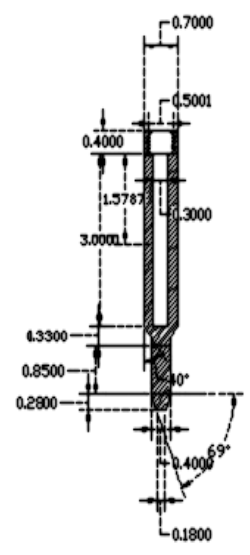

Injector Needle

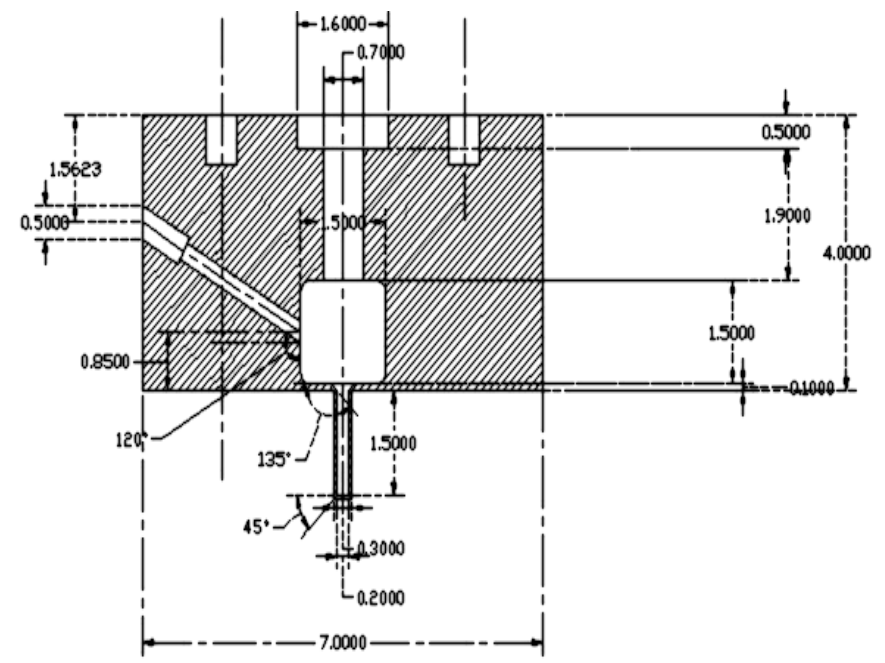

Injector Sac volume

Figure 3. (a) Photograph of the solenoid valve, (b) circuit diagram for the power supply to the solenoid valve, and (c) detailed drawing of the injector system.

\section{Test model}

In the present investigation, a $60^{\circ}$ apex-angle blunt cone model with $70 \mathrm{~mm}$ base diameter and bluntness ratio of 0.857 is used. The model is equipped with thin film gauges and internally mounted accelerometer-based balance system to measure both the convective surface heat transfer rates over the model surface and aerodynamic drag on the model simultaneously. The schematic diagram and the photograph of the test model are shown in figures $2 \mathrm{a}$ and $\mathrm{b}$ respectively.

Injecting the supersonic jet during the steady hypersonic flow in the test section is the most challenging task in the present investigations as the total test time in the tunnel is less than one millisecond. For this purpose we have built a gas-injection system using a solenoid valve shown in figure 3 . The injector system consists of a solenoid valve shown in figure $3 \mathrm{a}$ which is operated by a 24 VDC supplied by the electronic circuit, shown in figure $3 \mathrm{~b}$, after receiving an external trigger signal. The solenoid valve supplies the gas to the orifice at the stagnation point of the model from the reservoir connected to the gas cylinder as shown in figure $3 \mathrm{c}$. The operational characteristics of the gas injector system are determined using a test chamber shown in figure $4 \mathrm{a}$. The test chamber was evacuated to the pressure levels identical to the levels in the test section and dump tank assembly, and a pressure probe was mounted opposite to the supersonic jet coming out of the injector system. Typical driver-voltage signal and pressure signal from the probe are shown in figure $4 \mathrm{~b}$. From these signals, it is seen that the solenoid opens completely in about $15 \mathrm{~ms}$ after receiving the driver signal. Thus, in order to synchronize the counterflowing supersonic jet from the stagnation point of the test model with the arrival of the hypersonic flow in the test section, it is essential to actuate the solenoid valve about $15 \mathrm{~ms}$ before the establishment of hypersonic flow in the test section.

It is found that the time interval between the bursting of the metallic diaphragm and the arrival of the test flow in the test section is about $15 \mathrm{~ms}$. Hence, the electronic signal output from a pressure gauge mounted in the driver section of the shock tube is used to trigger the 
(a)

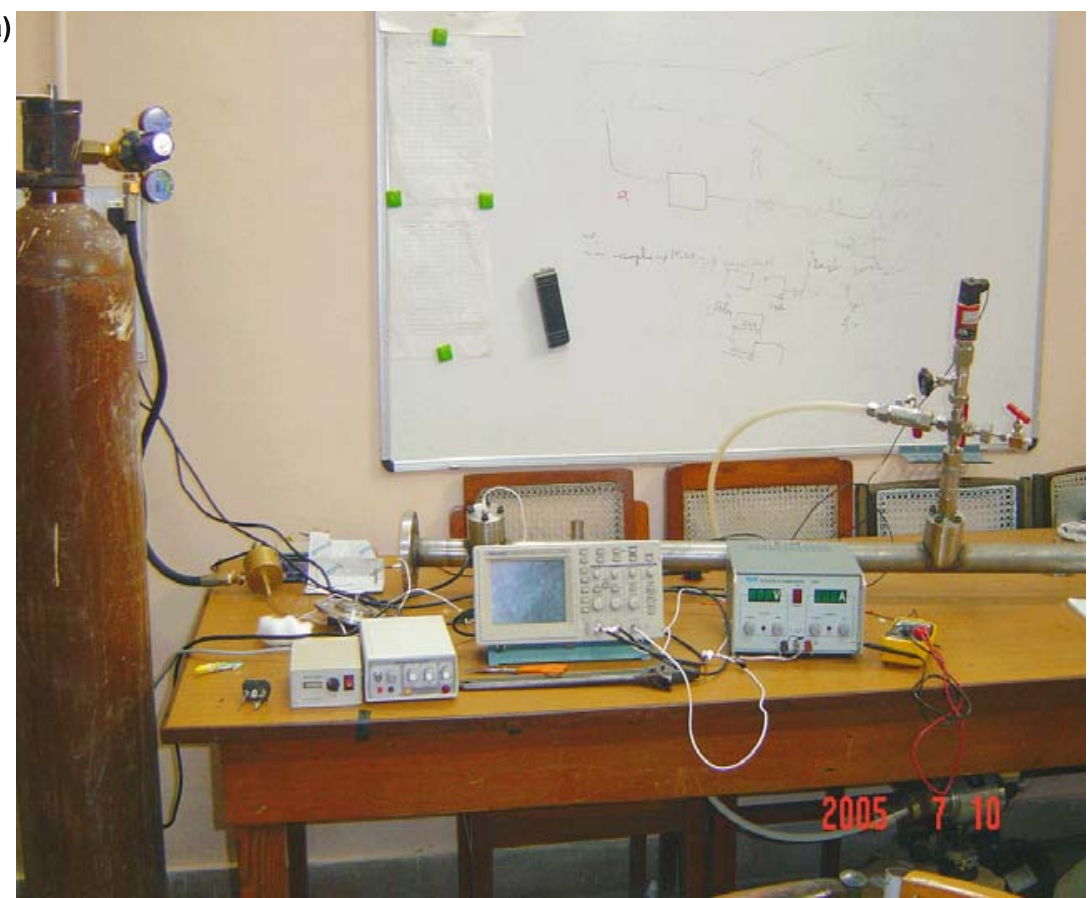

(b)

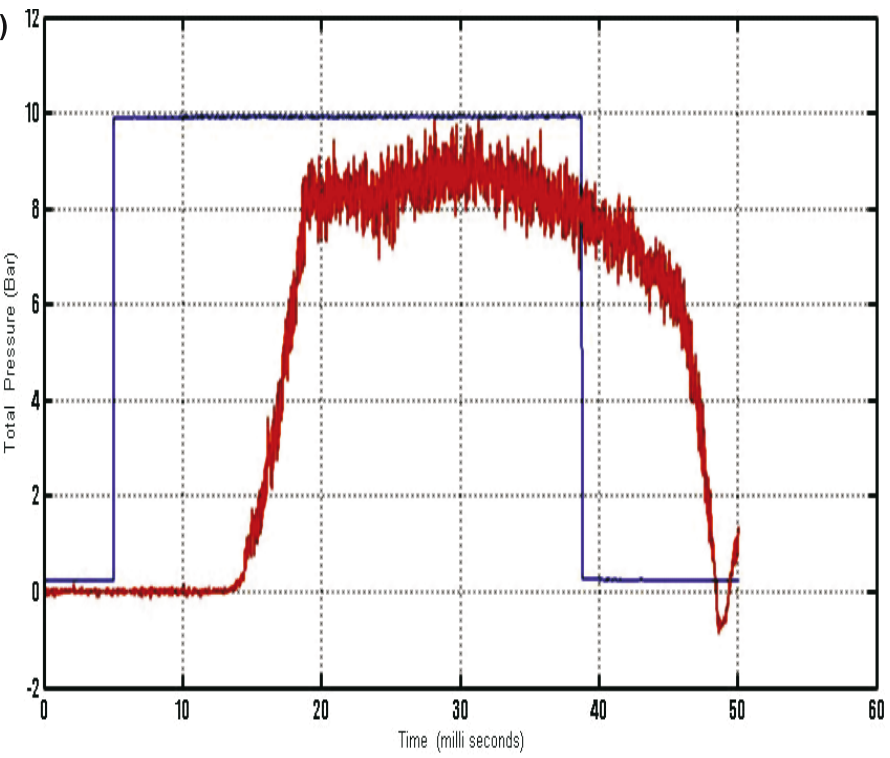

Figure 4. (a) Photograph of the calibration set up for measuring the performance of the gas injection system and (b) the input square voltage signal to the solenoid valve and the response signal from the pressure sensor mounted inside the test chamber. 


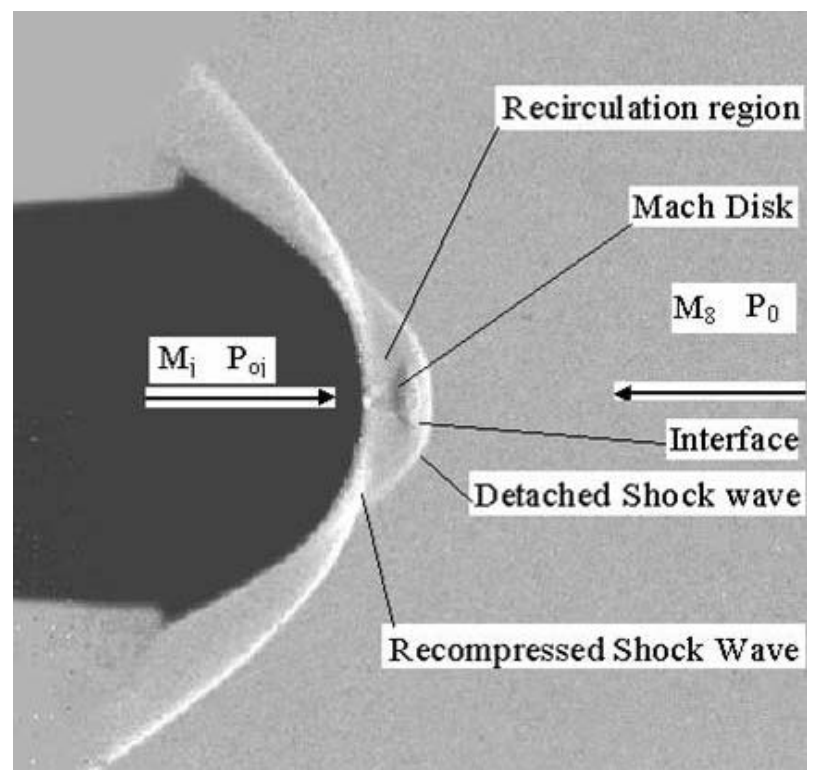

Figure 5. Features of hypersonic flow over a blunt cone with an opposing supersonic jet at steady state.

DC power supply, as shown in figure 1 . The schlieren picture shown in figure 5 clearly shows the supersonic jet emerging from the stagnation point of the test model moving opposite to the hypersonic test flow. The opposing jet interacts with the oncoming hypersonic flow causing the bow shock wave in front of the blunt model to stand away from the surface which results in the reduction of aerodynamic drag (Balla Venukumar et al 2006).

\section{Results and discussion}

Using a forward-facing spike is an effective means of reducing the aerodynamic drag for high-speed flight vehicles (Menezes et al 2003). The aerospike creates a conical dead-air region of separated flow which effectively masks the blunt nose of the body. The incoming flow effectively sees a streamlined cone of air instead of the actual blunt nose. However, the spike becomes hot and ablates as a result of large stagnation temperature, and hence requires frequent replacement or active cooling. This problem is overcome by replacing the physical aerospike with a forward-facing sonic jet (Srinivasan \& Chamberlain 2004; Balla Venukumar et al 2006). In the present set of experiments, the aerodynamic drag for the blunt cone is measured with and without supersonic jet at Mach 8 using an accelerometer-based force balance system. We have used both nitrogen and helium supersonic jets in this study. The experimental conditions and the measured values of the drag coefficient and the percentage of reduction in the drag coefficient from some of the preliminary set of experiments are presented in table 1 . The experimental data show that the drag coefficient for the $60^{\circ}$ apex-angle blunt cone reduces substantially in presence of the forward-facing supersonic jet. Variation of the drag coefficient with pressure in the injection chamber is shown in figure 6(a) and the percentage reduction of drag coefficient is shown in figure $6(\mathrm{~b})$. These results demonstrate the drag-reduction capabilities of the counterflow supersonic jet for blunt body in hypersonic flow. Detailed study of the effect of jet pressure on the aerodynamic drag was carried out subsequently and the results are reported in the recent paper (Balla Venukumar et al 2006). 
(a)

Jet Injection Pressure Vs Ca

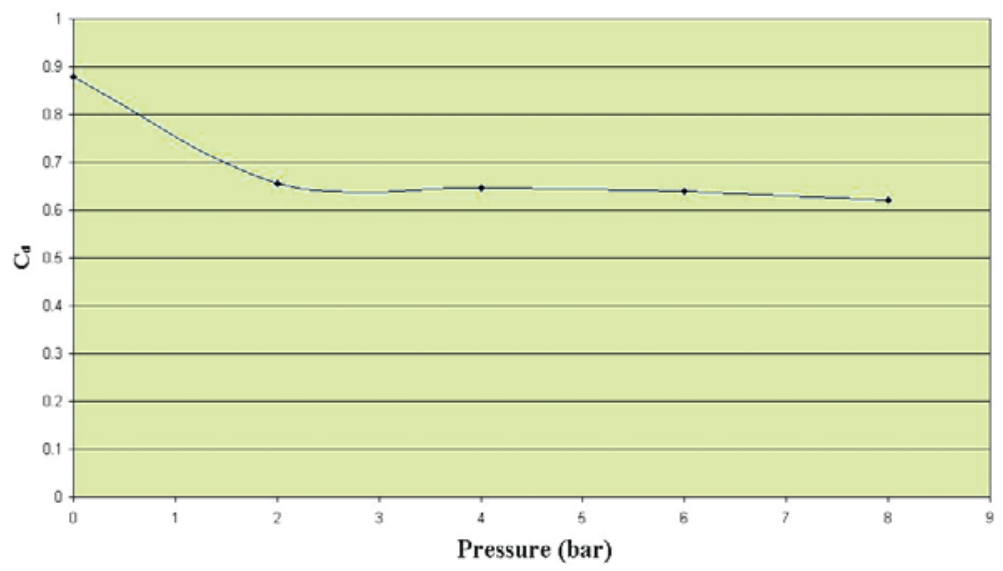

(b) Jet injection pressure Vs Reduction in $\mathrm{C}_{\mathrm{d}}(\%)$

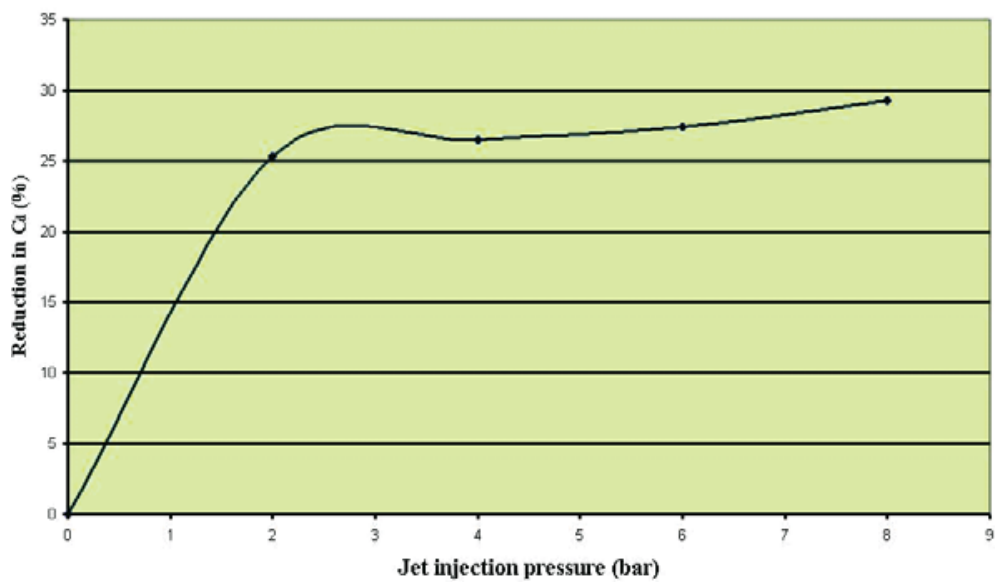

Figure 6. (a) Variation of drag coefficient with the injector pressure and (b) percentage of drag reduction as a function of injector pressure.

Table 1. Experimental data.

\begin{tabular}{|c|c|c|c|c|c|c|}
\hline $\begin{array}{l}P o \\
\text { (bar) }\end{array}$ & $\begin{array}{l}P \infty \\
(\mathrm{Pa})\end{array}$ & $\begin{array}{l}T \infty \\
(\mathrm{K})\end{array}$ & $\begin{array}{c}\text { Injector } \\
\text { pressure (bar) }\end{array}$ & $\begin{array}{l}\text { Injected } \\
\text { Gas }\end{array}$ & $\mathrm{Cd}$ & $\begin{array}{l}\text { Reduction in } \\
\text { Cd }(\%)\end{array}$ \\
\hline $14 \cdot 5$ & 148.5 & 158.9 & 0 & - & 0.879 & - \\
\hline 21.4 & $219 \cdot 2$ & $172 \cdot 4$ & $2 \cdot 5$ & $\mathrm{~N} 2$ & 0.656 & $25 \cdot 3$ \\
\hline $22 \cdot 0$ & $225 \cdot 5$ & $175 \cdot 5$ & $4 \cdot 5$ & $\mathrm{~N} 2$ & 0.727 & $17 \cdot 3$ \\
\hline $22 \cdot 0$ & $225 \cdot 5$ & $175 \cdot 5$ & 4.0 & $\mathrm{He}$ & 0.646 & $26 \cdot 5$ \\
\hline $23 \cdot 4$ & 239.4 & $178 \cdot 3$ & $6 \cdot 0$ & $\mathrm{He}$ & 0.639 & 27.4 \\
\hline $19 \cdot 2$ & $196 \cdot 8$ & $168 \cdot 2$ & $6 \cdot 0$ & $\mathrm{He}$ & 0.651 & 25.9 \\
\hline $22 \cdot 0$ & $225 \cdot 5$ & $175 \cdot 5$ & $6 \cdot 0$ & $\mathrm{He}$ & 0.698 & $20 \cdot 9$ \\
\hline $24 \cdot 1$ & 247.7 & $180 \cdot 7$ & $8 \cdot 0$ & $\mathrm{He}$ & 0.621 & $29 \cdot 3$ \\
\hline
\end{tabular}




\section{Conclusions}

We have presented the results of the experimental investigation of aerodynamic drag reduction for a $60^{\circ}$ apex-angle blunt cone configuration flying at hypersonic Mach number of 8 using a forward-facing supersonic gas jet. The measurements show an appreciable reduction in drag for the nominal flow conditions achieved in the hypersonic shock tunnel. The percentage of drag reduction for nitrogen and helium jets is identical and it is independent of the injector pressure beyond 2 bar. The results presented here are from the preliminary exploratory experiments where no effort has been made to optimize the supersonic jet parameters. Also, we have not investigated the effect of supersonic jet on the surface heat-transfer rates. These studies are currently underway.

This paper is dedicated to Dr P R Viswanath for his contributions to experimental research in aerodynamics. We would like to express our thanks to Drs G Jagadeesh and Niranjan Sahoo, and S Sravanan, K Nagashetty, K Satheesh, Reddappa, Vinayak Kulkarni and Rajagopal for their help in the experimental work. This work is partially supported by the AR \& DB, Department of Science \& Technology, New Delhi.

\section{References}

Balla Venukumar, Jagadeesh G, Reddy K P J 2006 Counterflow drag reduction by supersonic jet for a blunt body in hypersonic flow. Phys. Fluids 18: Art. No. 118104

Josyula E, Pinney M, Blake W M 2001 Application of a counterflow drag reduction technique in high speed systems. AIAA Paper 01-2437.

Hayashi K, Asoy S 2003 Effect of pressure ratio on aerodynamic heating reduction due to opposing jet. AIAA Paper 03-4041

Menezes V, Saravanan S, Jagadeesh G, Reddy K P J 2003 Experimental investigations of hypersonic flow over highly blunted cones with aerospikes. AIAA J. 41: 1955-1966

Menezes V, Kumar S, Maruta K, Reddy K P J, Takayama K 2005 Hypersonic flow over a multi-step afterbody, Shock Waves 14: 421-424

Peter F I, Donn B K 1987 High-speed aerodynamics of several blunt-cone configurations. J. Spacecr. Rockets 24: 127-132

Reddy K P J, Jagadeesh G, Menezes V, Sahoo N 2006 Experimental investigations of aerodynamic drag management for hypersonic vehicle configurations. In Proc. 11th Asian Congress of Fluid Mechanics, Kuala Lumpur, Malaysia

Reddy N M, Nagashetty K, Jagadeesh G, Reddy K P J 1996 Review of research investigations during 1975-1995 in IISc hypersonic shock tunnel (HST1) at hypersonic Mach numbers. Sädhanā 21: 741-773

Sahoo N, Kulkarni V, Saravanan S, Jagadeesh G, Reddy K P J 2005 Film cooling effectiveness on a large angle blunt cone flying at hypersonic speed. Phys. Fluids 17(3): 1-11

Satheesh K, Jagadeesh G 2005 An experimental study of the effect of plasma injection on the wave drag on a blunt body in a hypersonic flow. Shock Waves - Proc. 25th Int. Symp. on Shock Waves, Bangalore (eds) G Jagadeesh, E Arunan, K P J Reddy, pp 89-93

Srinivasan G R, Chamberlain R R 2004 Drag reduction of spiked missile by heat addition. AIAA J. paper 04-4714 